\title{
PERANCANGAN ANIMASI INTERAKTIF LINGKUNGAN ALAM DAN BUATAN MENGGUNAKAN VIDEO MOTION
}

\author{
Teti Solihah $^{1}$, Jenie Sundari ${ }^{2}$ \\ ${ }^{1,2}$ Program Studi Teknik Informatika, STMIK Nusa Mandiri \\ Jl. Kramat Raya No.18, RT.5/RW.7, Kwitang, Kec. Senen, Kota Jakarta Pusat 10450 \\ Email: tetisoli2610@gmail.com, jenie.jni@ nusamandiri.ac.id
}

Article history

Received May 11, 2020

Revised May 27, 2019

Accepted May 28, 2019

Available online May 31, 2020

Keywords

Interactive Animations

Natural and Artificial

Environments

Montion Videos
Riwayat

Diterima 11 Mei 2020

Revisi 27 Mei 2020

Disetujui 28 Mei 2020

Terbit 31 Mei 2020

\section{Kata Kunci}

Animasi Interaktif

Alam dan Buatan Video

Lingkungan

Motion

\section{Abstract}

A Computer is a piece of equipment that can be used to facilitate human work, one of which is in the field of education. Interactive animation is a learning medium that is popular today. Delivery of material, making a significant influence in the field of conveying information manually. Making interactive animations of natural and artificial environments using montion videos, aims to add learning tools for teachers to attract students interest and attention in learning. Interactive animation program that was buil using the concept of learning at SMK Yapinda in social studies, one of which is the interactive animation theme of natural and artificial environments. Data collection methods used by the author in the design of interactive animations is by direct obsevation of teaching and learning activities from the point of view of the teacher and students in order to obtain an optimal picture. In this interactive animation program there are learning processes to recognize the natural and artificial environment, interesting pictures and audio to improve student absorption of the contents of the material. In this interactive animation it is expected to make students feel comfortable in learning so as to improve student achievement.

\section{Abstrak}

Komputer merupakan suatu peralatan yang dapat digunakan untuk mempermudah pekerjaan manusia, salah satunya di bidang pendidikan. Animasi interaktif merupakan media pembelajaran yang cukup populer saat ini. Penyampaian materi, menjadikan pengaruh yang signifikan dibidangkan dengan menyampaikan informasi secara manual. Pembuatan animasi interaktif lingkungan alam dan buatan menggunakan video motion, bertujuan untuk menambah sarana pembelajaran bagi guru dalam menarik minat dan perhatian siswa-siswi dalam belajar. Program animasi interaktif yang dibangun menggunakan konsep pembelajaran pada SMK Yapinda dalam pelajaran IPS, salah satunya tema animasi interaktif lingkungan alam dan buatan. Metode pengumpulan data yang digunakan oleh penulis dalam perancangan animasi interaktif adalah dengan observasi secara langsung terhadap kegiatan belajar mengajar dari sudut pandang guru dan siswa guna mendapatkan gambaran yang optimal. Dalam program animasi interaktif ini terdapat proses-proses pembelajaran mengenal lingkungan alam dan buatan, gambar- gambar yang menarik serta audio untuk meningkatkan daya serap siswa terhadap isi materi. Dalam animasi interaktif ini diharapkan membuat siswa-siswi merasa nyaman dalam belajar sehingga dapat meningkatkan prestasi belajar siswa. 


\section{PENDAHULUAN}

Lingkungan Hidup adalah suatu program pendidikan untuk membina anak peserta didik agar memiliki pengertian, kesadaran, sikap, dan perilaku yang rasional serta bertanggung jawab tentang pengaruh timbal balik antara penduduk dengan lingkungan hidup dalam berbagai aspek kehidupan manusia. Pendidik lingkungan hidup bukanlah mata pelajaran yang berdiri sendiri. Namun, di integrasikan kedalam suatu bidang studi di sekolah.

Dalam kehidupan berbangsa dan bernegara, wilayah bukanlah hanya sekedar pengertian geografis. Dalam pengertian termasuk di dalamnya rakyat yang mendiami wilayah. Rakyat ini yang secara menyeluruh merupakan pemilik kedaulatan Republik Indonesia serta menjadi pelaksana dan tujuan pembangunan yang telah meningkatkan kita bahwa keberhasilan ditentukan oleh disiplin dan semangat penyelenggara negara, tetapi juga oleh peran serta rakyat Indonesia. Setiap daerah berupa menggali potensi sumber daya alam, potensi sumber daya manusia, termasuk potensi budaya untuk dijadikan sebagai sumber pendapatan bagi penyelenggaraan pembangunan, salah satunya adalah sektor pariwisata.

Lingkungan alam adalah segala sesuatu yang ada di alam dan diciptakan oleh Tuhan untuk manusia agar dapat dimanfaatkan dalam kehidupannya. Kenampakan alam di muka bumi ini berbeda-beda. Lingkungan alam dibagi menjadi dua macam, yaitu lingkungan darat dan lingkungan perairan. Contoh dari lingkungan darat adalah gunung, hutan, dataran, rendah, dataran tinggi, dan pegunungan. Sedangkan contoh lingkungan perairan adalah danau, sungai, laut dan selat. Sedangkan lingkungan buatan adalah segala sesuatu yang dibuat oleh manusia dan bertujuan untuk memenuhi kebutuhan hidup manusia. Contoh lingkungan buatan adalah bandara, stasiun, sekolah, jalan, jembatan dll.

Media pembelajaran merupakan segala sesuatu yang bersifat menyalurkan pesan dan dapat merangsang pikiran, perasaan, dan kemauan siswa yang dapat mendorong terjadinya proses belajar pada dirinya. Dengan adanya alat bantu dapat mewakili sesuatu yang tidak dapat disampaikan oleh guru dengan katakata atau kalimat".

Masalah yang dihadapi yaitu tidak tersedianya media pembelajaran interaktif yang membantu guru dalam memberikan materi pengenalan lingkungan alam dan buatan, kurang efektifnya media pembelajaran pengenalan lingkungan alam dan buatan yang ada sehingga menyulitkan siswa-siswi untuk mengingat pelajaran dan tidak ada pembelajaran yang menggunakan animasi interaktif untuk guru dan siswa- siswi dalam proses belajar mengajar.

\section{TINJAUAN PUSTAKA}

\section{Pengertian Multimedia}

Menurut (Sugiani, Rosalina, \& Yunan, 2014)

Multimedia berasal dari kata multi dan media. Multi berasal dari bahasa Latin yaitu nouns yang berarti banyak atau bermacam-macam. Sedangkan kata media berasal dari bahasa Latin, yaitu medium yang berarti perantara atau sesuatu yang dipakai untuk menghantarkan, menyampaikan, atau membawa sesuatu. Berdasarkan itu multimedia merupakan perpaduan antara berbagai media (format file) yang berupa teks, gambar (vektor atau bitmap), grafik, sound, animasi, video, interaksi, dan lain- lain yang dikemas menjadi file digital (komputerisasi), digunakan untuk menyimpan atau menghatar pesan kepada publik.

\section{Motion}

Menurut (Putri, 2017) Motion bisa dikatakan sejenis dengan infographic, tetapi menggunakan cuplikan video atau animasi untuk membuat rangkaian gerak ilusi. Motion pada umumnya merupakan gabungan dari potongan-potongan desain yang berbasis media visul yang menggabungkan bahasa film dengan desain grafis, seperti memasukan elemen-elemen yang berbeda seperti desain $2 \mathrm{D}$ atau 3D, animasi, video, ilustrasi, fotografi, dan musik. Termasuk di dalamnya yaitu, tipografi dan grafis yang dapat terlihat sebagai judul untuk film, pembuka program televisi, bumper, dan elemen-elemen grafis yang muncul di televisi. Namun, video atau film dari objek yang bergerak belum dikategorikan sebagai bagian dari motion, kecuali jika video atau film tersebut dikombinasikan dengan beberapa elemen desain, seperti bentuk, jenis, atau baris. 


\section{Adobe After Effect}

Menurut (Maharani \& Hotami, 2017) merupakan software pembuat animasi dan special effect yang sangat populer dan sudah diakui kecanggihannya. Kelengkapan fasilitas dan kemampuannya yang luar biasa menjadikan software ini banyak dipakai oleh para animator dan desain grafis karena keberadaannya benarbenar mampu membantu dan memudahkan pemakai dalam menyelesaikan berbagai jenis pekerjaan visual. Adobe After Effect adalah produk piranti lunak yang dikembangkan oleh Adobe, digunakan untuk film dan pos produksi pada video. Pada awalnya merupakan sebuah software produk dari Macromedia yang sekarang sudah menjadi salah satu produk Adobe.

\section{Adobe Photoshop CS3}

Menurut (Santi \& Sukadi, 2014) Menyimpulkan : Photoshop CS3 digunakan untuk memodifikasi gambar atau foto secara profesional baik meliputi modifikasi obyek yang sederhana maupun yang rumit sekalipun. Kelengkapan filtur yang ada didalam photoshop inilah yang akhirnya membuat software ini banyak digunakan oleh grafis professional.

\section{Storyboard}

Menurut (Fitria \& Septiana, 2016) merupakan perorganisasi grafik, contohnya adalah sederetan ilustrasi atau gambar yang ditampilkan berurutan untuk keperluan visualisasi awal dari suatu file animasi, atau urutan media interaktif.

\section{Adobe Premier Pro}

Menurut (Yulandina, Antoni, \& Firmanda, 2018) adalah software editing video yang memiliki fitur lengkap dan telah populer digunakan di masyarakat secara luas. Karena masih dalam satu kelompok dengan Adobe. Adobe Premier Pro memiliki kesamaan interface dengan Adobe After Effects dan Adobe Photoshop.

\section{Pengujian Black Box}

Menurut (Rosa \& Shalahuddin, 2018) "Black Box Testing adalah menguji perangkat lunak dari segi spesifikasi fungsional tanpa menguji desain dan kode program. Pengujian dimaksudkan untuk mengetahui apakah fungsi-fungsi, masukan, dan keluaran dari perangkat lunak sesuai dengan spesifikasi yang dibutuhkan".

\section{HASIL DAN PEMBAHASAN}

\section{Karakteristik Software}

Dalam merancang animasi interaktif lingkungan alam dan buatan harus berpedoman pada karakteristik. Karakteristik media pembelajaran interaktif lingkungan alam dan buatan ini yaitu:

- Konsep

Konsep merupakan abstraksi suatu ide atau gambaran mental, yang dinyatakan dalam suatu kata atau simbol. Konsep dinyatakan juga sebagai bagian dari pengetahuan yang dibangun dari berbagai macam karakteristik. Mempelajari konsep lingkungan alam maupun buatan akan berpengaruh pada kelangsungan perikehidupan dan kesejahteraan manusia serta makhluk hidup lainnya.

\section{- Storyboard}

Sketsa gambar yang disusun berurutan sesuai dengan naskah, dengan storyboard kita dapat menyampaikan ide cerita kita kepada orang lain dengan lebih mudah, karena kita dapat menggiring khayalan seseorang mengikuti gambar-gambar yang tersaji, sehingga menghasilkan persepsi yang sama pada ide cerita kita.

\section{- Sketsa Gambar}

Sketsa sangat erat kaitannya dengan seni menggambar ataupun melukis. Biasanya sketsa dijadikan kerangka sebelum membuat suatu gambar atau lukisan, sehingga kesalahankesalahan dalam menggambar dapat di minimalisir.

- Desain Gambar

Desain gambar dirancang sebagai suatu proses komunikasi menggunakan elemen visual untuk menciptakan persepsi akan suatu pesan yang disampaikan.

- Animasi

Animasi ditujukan sebagai dasar sebuah seni dalam mempelajari gerakan suatu objek, dan gerakan merupakan sesuatu hal yang paling diutamakan agar suatu objek atau karakter dapat terlihat nyata. Animasi juga mewujudkan suatu teknik untuk menciptakan sebuah karya audio dan visual yang berdasarkan pada pengaturan waktu dan gambar.

- Editing

Editing digunakan sebagai proses memilih dan menyiapkan media penulisan, fotografi, visual, audible, dan film sehingga mampu memanipulasi gambar. 
- Rendering

Rendering adalah proses dari membangun gambar dari sebuah model melalui program komputer sehingga menghasilkan gambar fotorealistik dan non-fotorealistik dari model 2D dan 3D.

\section{Use Interface}

User interface merupakan sebuah tampilan dari sebuah kerangka dasar menjadi desain yang digunakan oleh user:

a. Tampilan Opening

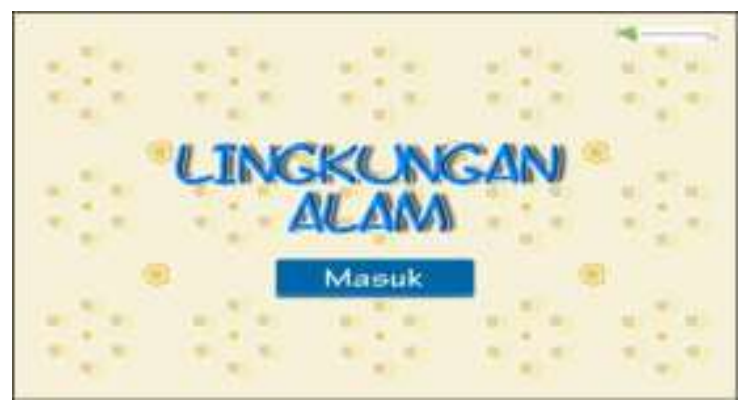

Gambar 1. Tampilan Opening

b. Tampilan Menu Utama

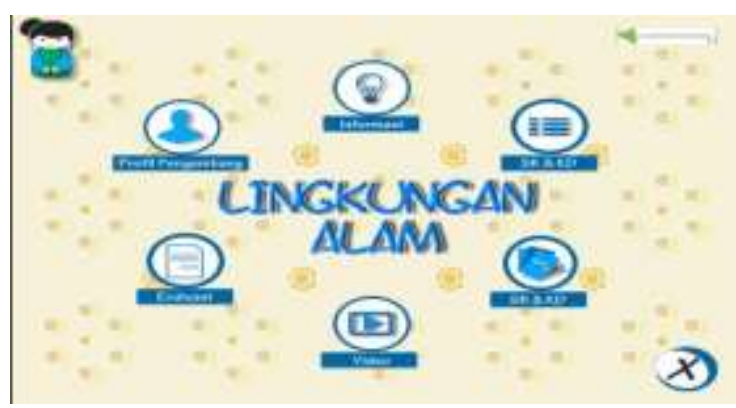

Gambar 2. Tampilan Menu Utama

c. Tampilan Scale World

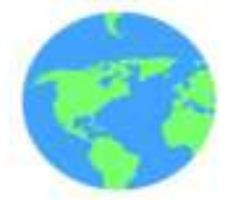

Gambar 3. Tampilan Scale Word d. Tampilan Pop up, a man Walking

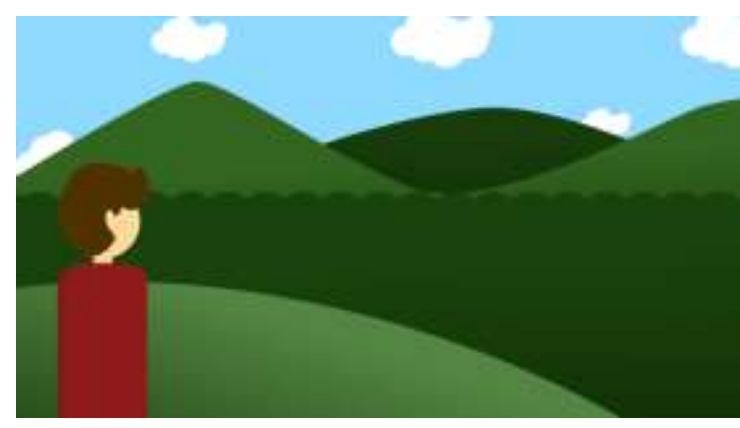

Gambar 4. Tampilan Pop up, a man Walking

e. Tampilan Pop up Image

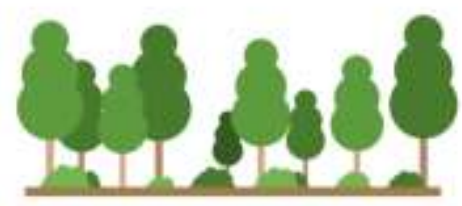

Gambar 5. Tampilan Pop up Image

f. Tampilan Pop up Buildings

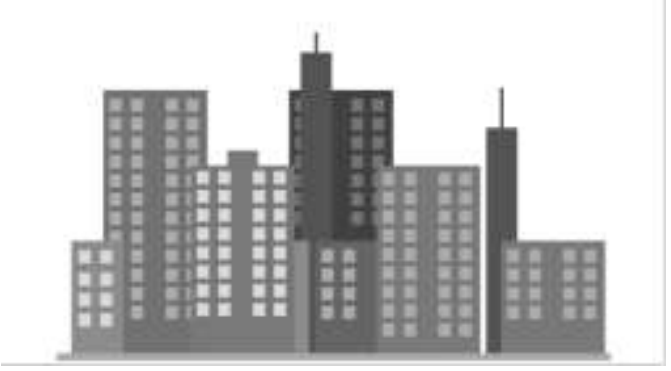

Gambar 6. Tampilan Pop up Buildings

g. Tampilan Pop up all Asset

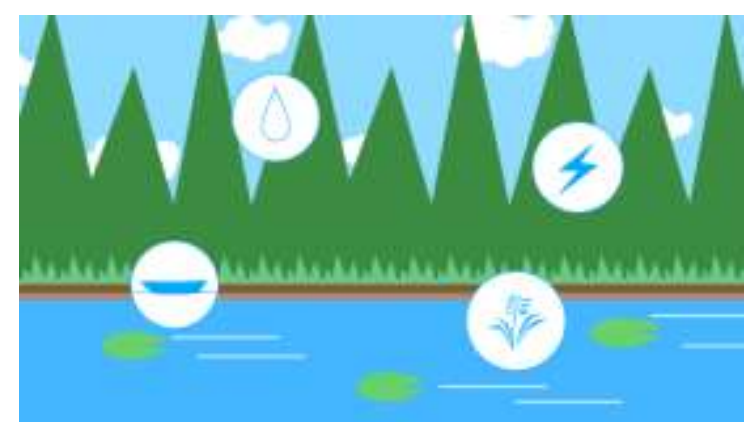

Gambar 7. Tampilan Pop up all Asset

JIKA $\mid 108$ 
h. Tampilan Scale out, wave looping

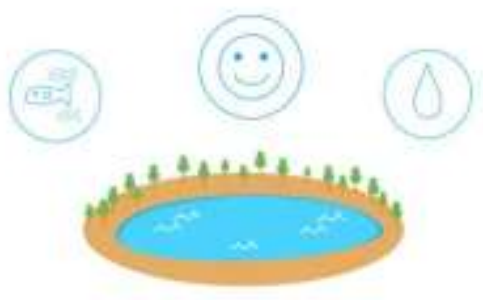

Gambar 8. Tampilan Scale out, wave looping

i. Tampilan Pop up all Asset

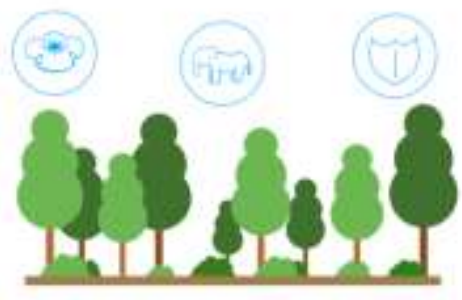

Gambar 9. Tampilan Pop up all Asset

j. Tampilan Pop up all asset, Wave loop

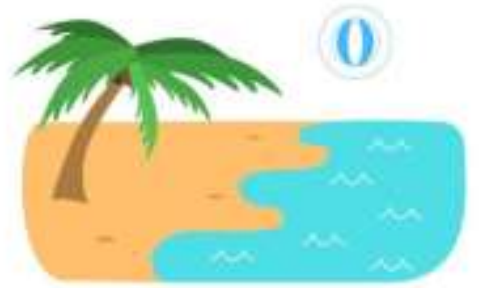

Gambar 10. Tampilan Pop up all asset, Wave loop k. Tampilan Pop up building, Transportations

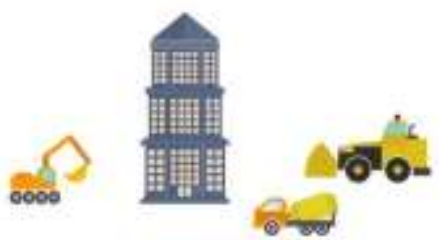

Gambar 11. Tampilan Pop up building, Transportations

1. Tampilan Pop up all Asset

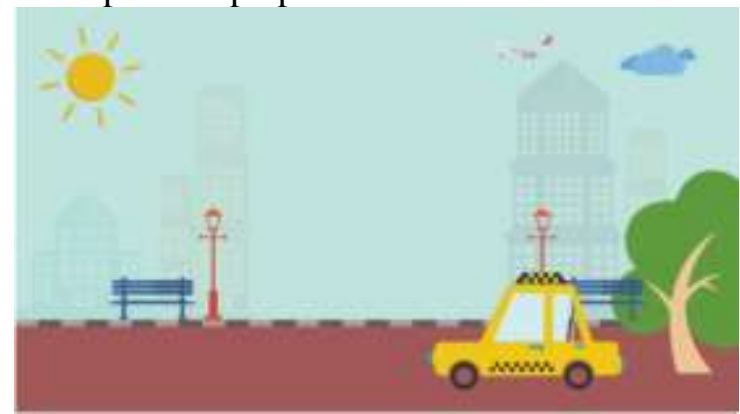

Gambar 12. Tampilan Pop up all Asset

m. Tampilan Popup all Asset, Transportations

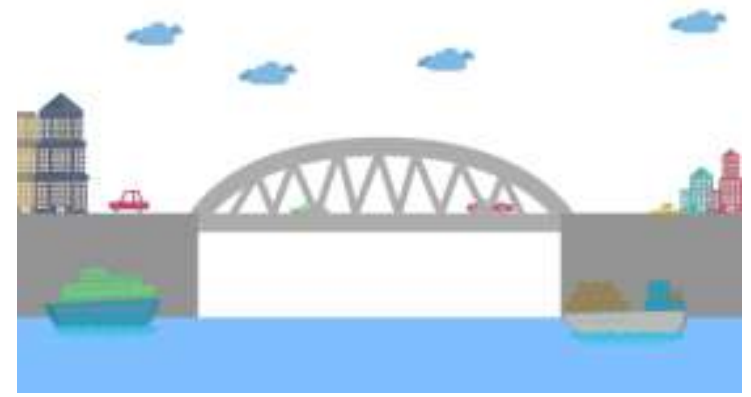

Gambar 13. Tampilan Popup all Asset, Transportations 
n. Tampilan Popup all Asset

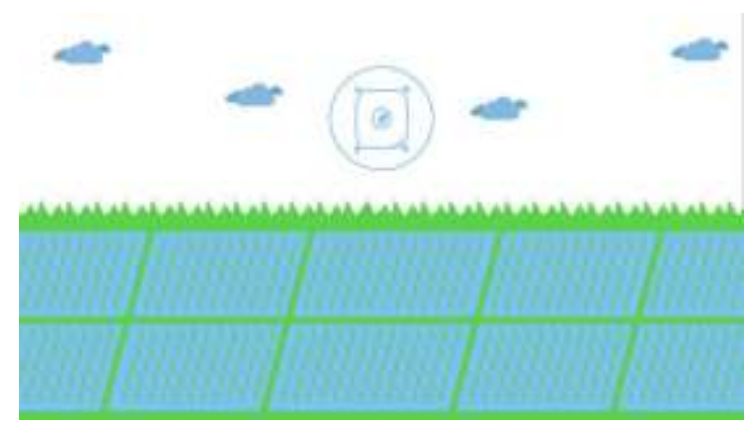

Gambar 14. Tampilan Popup all Asset

o. Tampilan Popup Trash

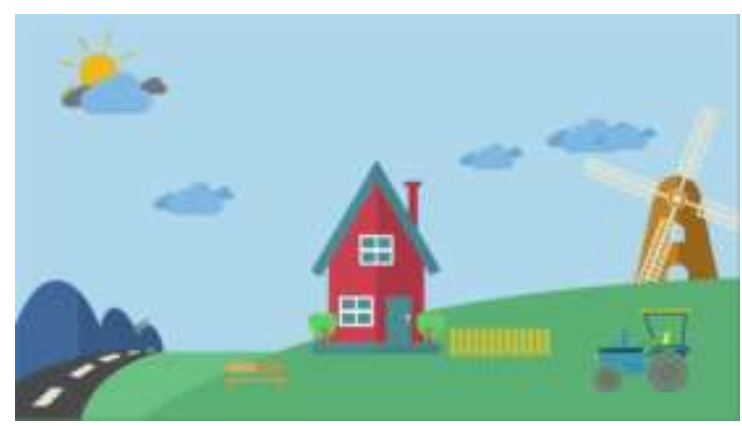

Gambar 15. Tampilan Popup Trash

p. Tampilan Slow Scale out, pop up all Asset

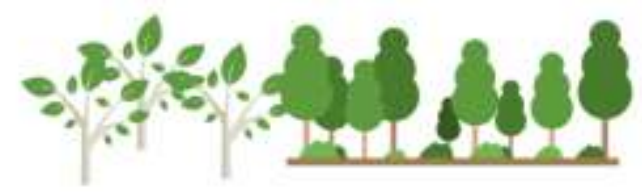

Gambar 16. Tampilan Slow Scale out, pop up all Asset q. Tampilan Popup all Asset

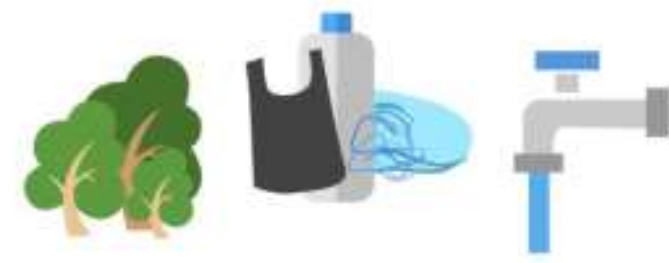

Gambar 17. Tampilan Popup all Asset

r. Tampilan Popup Text

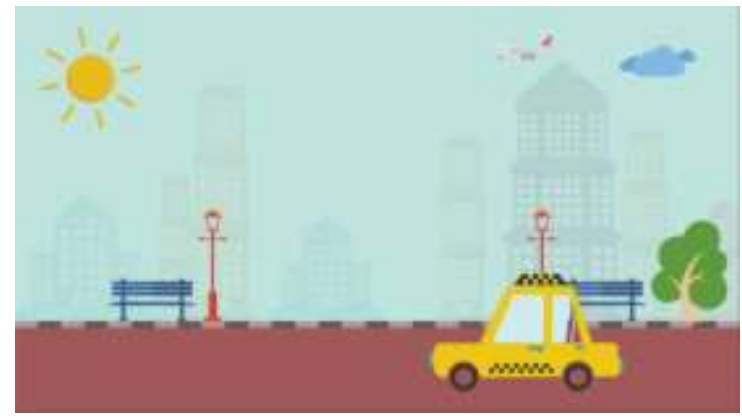

Gambar 18. Tampilan Popup Text

s. Tampilan Popup Text

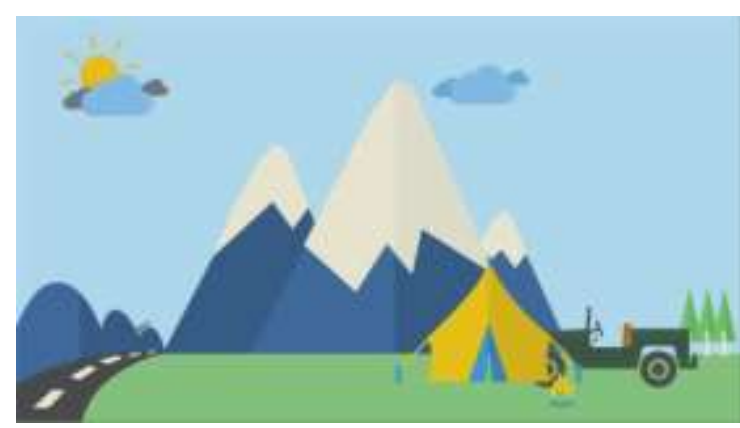

Gambar 19. Tampilan Popup Text

\section{Pengujian Black Box}

Aplikasi pembelajaran animasi interaktif yang telah dibuat selanjutnya diuji melalui teknik pengujian perangkat lunak yang meliputi pengujian black box. Pengujian dilakukan untuk memastikan bahwa semua statement pada program telah dieksekusi paling tidak satu kali selama pengujian dan bahwa semua kondisi logis telah diuji. 
Tabel 1. Pengujian Black Box

\begin{tabular}{|c|c|c|c|}
\hline $\begin{array}{l}I N P U \\
T / E V \\
E N T\end{array}$ & PROSES & $\begin{array}{l}\text { OUTP } \\
\text { UT/NE } \\
X T \\
\text { STAGE }\end{array}$ & $\begin{array}{l}\text { HASI } \\
L \\
P E N \\
G U J \\
I A N\end{array}$ \\
\hline $\begin{array}{l}\text { Anch } \\
\text { or } \\
\text { Point }\end{array}$ & $\begin{array}{l}\text { \{value[0],con } \\
\text { tent("Rectagl } \\
\text { e } \\
\text { 1").content("“ } \\
\text { Rectangle } \\
\text { Path } \\
\text { 1").size[1]/2] }\end{array}$ & $\begin{array}{l}\text { Mengat } \\
\text { ur Posisi } \\
\text { Anchor } \\
\text { Point }\end{array}$ & $\begin{array}{l}\text { Sesu } \\
\text { ai }\end{array}$ \\
\hline $\begin{array}{l}\text { Loopi } \\
\text { ng }\end{array}$ & $\begin{array}{l}\text { loopOutDura } \\
\text { tion(type = } \\
\text { "cycle", } \\
\text { duration = 0) }\end{array}$ & $\begin{array}{l}\text { Membu } \\
\text { at } \\
\text { Animas i } \\
\text { Loopin g }\end{array}$ & $\begin{array}{l}\text { Sesu } \\
\text { ai }\end{array}$ \\
\hline
\end{tabular}

\section{KESIMPULAN}

Dalam pembahasan mengenai animasi interaktif lingkungan alam dan buatan ini menggunakan video motion, sehingga penulis menyimpulkan bahwa : Dengan aplikasi Animasi interaktif ini menjadi media alternatif dalam pembelajaran lingkungan alam dan buatan. Dengan dibuatnya animasi interaktif ini, maka metode pembelajaran lingkungan alam dan buatan lebih menyenangkan serta lebih fleksibel tidak terbatas tempat dan waktu untuk belajar. Animasi interaktif ini mudah dipahami karena dirancang dengan tampilan menarik, edukatif, dan tidak membuat siswasiswi cepat merasa bosen.

\section{REFERENSI}

Fitria, D., \& Septiana, A. (2016). Perancangan Animasi Interaktif Pengenalan Tata Surya Untuk Siswa Sekolah Berbasis Android.

Maharani, D., \& Hotami, M. (2017). Rendering Video Advertising Dengan Adobe After Effects Dan Photoshop. 2.

Putri, Y. D. R. (2017). Pembuatan Motion Graphics Sebagai Media Sosialisasi Dan Promosi Untuk Aplikasi Mobile Tranding Online Mandiri Sekuritas. 2.

Rosa, S. ., \& Shalahuddin, M. (2018). Rekayasa Perangkat Lunak Terstruktur Dan Berorientasi Objek. Bandung.

Santi, I. T., \& Sukadi. (2014). Pembuatan Games Pembelajaran Pengenalan Huruf Hijaiya Di Taman Kanak-kanak (TK) AzZalfa Sidoharjo Pacitan. 2.

Sugiani, Y., Rosalina, V., \& Yunan, I. (2014). Perancangan Aplikasi Edukatif Bebasis Multimedia Untuk Memnudahkan Siswa Belajar Membaca Pada Mata Pelajaran Bahasa Indonesia. 1.

Yulandina, A., Antoni, C., \& Firmanda, A. (2018). Optimalisasi Unsur Live Shoot Dan Motion Graphic Untuk Promosi Digital Lembaga Paud. 1. 